\title{
Routine Chemical Analysis of Tea Commercially Available in Ogun State, South West, Nigeria
}

\author{
Makanjuola, Olakunle Moses \\ Department of Food Technology, Federal Polytechnic, Ilaro, Ogun State, Nigeria
}

\begin{abstract}
Teabags commercially available in Ogun state, southwest Nigeria were evaluated for routine chemical analysis. Ten (10) teabags wer062, 620e randomly purchased from different department store, spread across the study area. The results of the analysis showed moisture content, ranging from 6.633\%-7.200\% while the crude fibre content ranged from 1.440\%-2.400\% respectively for all the samples. Tannin content ranged between 5.467 and 7.700 while total ash content for all the sample ranged from 3.667-5.133\%. The caffeine content as reveled by the result of the analysis showed value ranging from 0.207\%-1.833\%. acid insoluble matter (1.100\%-3.6679) potassium salt (13.733\%-17.067\%) and nitrogen matter (1.260\%-1.833\%) were also obtained. The overall results of the test showed that some of the teabags were adulterated when compared to standard.
\end{abstract}

Keywords: Routine, Chemical Analysis, Teabags, Commercially Available.

\section{INTRODUCTION}

Tea is known botanically as camellia sinensis. it is an automatic beverage commonly prepared by prepared by pouring hot or boiling water over the teabag of camellia sinensis. [1].Tea is the most popular flavoured and functional drink worldwide. Tea consist of the prepared leaves of varies spices of tea. For thousands of years the harvesting, processing and packaging of the leaf of camellia sinensis known as world wide as tea has developed as an integral part of the society and culture [2]

Most of the popular tea brands sold in the retail market in Ogun state, southwest Nigeria include Lipton tea, top tea, Richmond tea, nape tea, Tetley tea, chamouile tea, joko tea, dilmah tea, loyd tea, ahmad tea etc literature reveals that the chief constituent of tea packaged in tea bags are moisture, tannin, nitrogenous matter (including caffeine) inorganic matter (especially potassium salt) and crude fibre. [3].

Drinking tea helps to improve bone quality and strength, helps the body immune system fight off infection, increase the metabolic rate to burn up additional calories, has reduce risk of cardiovascular disease, help to reduce risk of breast or prostate cancer [4,5]. In the recent times there have been cases of adulteration of tea bags commercially available in the market as most of these tea bags do not contain nutrient claimed on their label. Therefore, this present work serve to reveal the wholesomeness of most of the tea bags commercially available at retail market in Ogun state southwest, Nigeria since compliance of standard quality parameter plays a significant role in ensuring product safety and health of consumers at large.

\section{Materials AND Methods}

Source of material; Tea bag samples were purchased from different stored spread across major towns in Ogun state, southwest, Nigeria. The tea bags already in cartons were kept in water proof polythene bags to prevent absorption of moisture.

Reagents used for the analyses over of analytical grade

Experimental Procedure;

The moisture content, tannin content, crude fibre, ash acid insoluble matter, potassium salt and nitrogenous matter were determined using standard methods [3]. For the caffeine content, $1 \mathrm{~g}$ of tea sample was weighted into $250 \mathrm{ml}$ separation funnel. $3 \mathrm{mg}$ of distilled water and $2 \mathrm{ml}$ ammonia solution were added, shook on a shaker for 2 minutes. $25 \mathrm{ml}$ aliquots of chloroform was added four times to 
contract the caffeine. Each extract was then washed in a separation funnel containing $10 \mathrm{ml}$ of potassium hydroxide solution in water. The washed chloroform extract was filtered through a what man filter paper (NO1) containing the extract and filtered extracts were collected into a $100 \mathrm{ml}$ volumetric flask, then made up to mark with chloroform. The absorption of sample as well as standard solution of range. $0.0 \mathrm{mg} / \mathrm{ml}$ were read in spectronic 21 spectrophotometer at a wavelength $275 \mathrm{~mm}$.

$\%$ Caffeine $=$ Absorbance of sample $\times$ Gradient $\times$ Dilution factor $\times 100$

$$
\text { Weight of the sample }
$$

Each determination was carried out in triplicates.

\section{Statistical Analysis}

The result of the analyses, were subjected to statistical analysis of variance (ANOVA) to determine by difference in sample means and Duncans Multiple Range Test (DMRT) was used to separate means at $\mathrm{p} \leq 0.05$ with statistical package for social science version 16.0 for windows (spss inc. illinious,USA)

\section{RESUltS AND DiscuSSION}

Table1. Chemical analysis of various tea brands commercially available in Ogun state, southwest Nigerian \pm

\begin{tabular}{|l|l|l|l|l|l|l|l|l|l|l|}
\hline Parameters & $\mathrm{A}$ & $\mathrm{B}$ & $\mathrm{C}$ & $\mathrm{D}$ & $\mathrm{E}$ & $\mathrm{F}$ & $\mathrm{G}$ & $\mathrm{H}$ & $\mathrm{I}$ & $\mathrm{J}$ \\
\hline Moisture\% & $6.633 \pm$ & $6.967 \pm$ & $6.667 \pm$ & $6.700 \pm$ & $6.667 \pm$ & $6.700 \pm$ & $7.200 \pm$ & $6.800 \pm$ & $6.767 \pm$ & $6.735 \pm$ \\
& 0.0577 & 0.0000 & 0.1523 & 0.0000 & 0.2082 & 0.1000 & 0.2000 & 0.1000 & 0.1528 & 0.2663 \\
\hline Tannin & $6.133 \pm$ & $5.467 \pm$ & $7.567 \pm$ & $7.700 \pm$ & $7.500 \pm$ & $7.367 \pm$ & $7.400 \pm$ & $7.133 \pm$ & $6.500 \pm$ & $7.687 \pm$ \\
& 0.1155 & 0.0577 & 0.1155 & 0.1000 & 5.1971 & 0.1528 & 0.000 & 0.577 & 0.0000 & 2.7683 \\
\hline Caffeine & $1.767 \pm$ & $0.207 \pm$ & $1.607 \pm$ & $1.407 \pm$ & $1.610 \pm$ & $1.817 \pm$ & $0.517 \pm$ & $1.433 \pm$ & $1.833 \pm$ & $1.398 \pm$ \\
& 0.0289 & 0.0115 & 0.0115 & 0.0115 & 0.0173 & 0.0288 & 0.0764 & 0.0577 & 0.0577 & 0.5529 \\
\hline Crude & $1.440 \pm$ & $1.850 \pm$ & $2.167 \pm$ & $2.033 \pm$ & $2.367 \pm$ & $2.267 \pm$ & $1.983 \pm$ & $2.400 \pm$ & $3.100 \pm$ & $2.132 \pm$ \\
Fibre & 0.0529 & 0.0500 & 0.0577 & 0.0577 & 0.1528 & 0.0577 & 0.5393 & 0.0000 & 0.1000 & 0.463 \\
\hline Total ash & $4.183 \pm$ & $3.667 \pm$ & $5.133 \pm$ & $4.300 \pm$ & $4.633 \pm$ & $4.500 \pm$ & $4.233 \pm$ & $4.433 \pm$ & $4.500 \pm$ & $4.368 \pm$ \\
& 0.0289 & 0.0500 & 0.0577 & 0.1000 & 0.1155 & 0.1000 & 0.2082 & 0.577 & 0.3000 & 0.3896 \\
\hline Acid & $1.100 \pm$ & $3.667 \pm$ & $2.167 \pm$ & $1.433 \pm$ & $1.433 \pm$ & $1.433 \pm$ & $1.533 \pm$ & $1.767 \pm$ & $1.817 \pm$ & $1.4307 \pm$ \\
Insoluble & 0.1000 & 0.0500 & 0.577 & 0.1000 & 0.0577 & 0.1155 & 0.0577 & 0.0577 & 0.0289 & 0.2919 \\
Matter & & & & & & & & & \\
\hline Potassium & $17.067 \pm$ & $14.850 \pm$ & $13.733 \pm$ & $16.367 \pm$ & $14.800 \pm$ & $15.433 \pm$ & $15.600 \pm$ & $15.533 \pm$ & $14.817 \pm$ & $15.650 \pm 1$ \\
Salt & 0.1528 & 0.500 & 0.2082 & 0.1528 & 0.100 & 0.2082 & 0.100 & 0.1155 & 0.3055 & .0664 \\
\hline Nitrogenous & $1.550 \pm 0$. & $1.433 \pm 0$. & $1.260 \pm 0$. & $1.750 \pm 0$. & $1.467 \pm 0$. & $1.633 \pm 0$. & $1.533 \pm 0$. & $1.750 \pm 0$. & $1.833 \pm 0$. & $1.529 \pm 0$. \\
matter & 0500 & 1155 & 0361 & 0500 & 0577 & 0577 & 0577 & 5000 & 3055 & 2999 \\
\hline
\end{tabular}

Values are means of triplicates with standard deviation

\section{DisCuSSION}

The result of the routine chemical composition of different tea bag brands commercially available in Ogun state, South west, Nigeria is as shown in table 2 the value obtained from these tea sample reveled significant difference $(\mathrm{p}<0.05)$ in different tea components such as moisture content, tannin, caffeine, crude fibre total ash, acid insoluble matter, potassium salt and nitrogen matter. Moisture content for all the samples ranged from 6.633-7.200\%. Moisture contents of tea bags forms one of the chief constituent of tea. A previous research reported 3.9-9.5\% moisture content for black tea [3]. The moisture contents for all the tea bags in this research work (6.633-7.200\%) may be due to the fermentation process and partly due to the packaging material which should maintain a constant level during storage of commercial tea. It was observed in a previous observed that $70 \%$ of commercial tea sample having moisture content of $6.6 \%$ or less and $30 \%$ samples containing moisture content up to $8 \%$ will have a negative effect on the shelf life of the product [6]. For better quality, the moisture content should be controlled at $2.5-6.5 \%$ [7].

Crude fibre is the insoluble and combustible organic residue which will remain after the sample has been treated under prescribed conditions. This empirical treatment provides a crude fibre consisting of largely of the cellulose content together with a proportion of lignin and hemi cellulose content of the sample. [3] The fibre content in the sample were $1.440 \%, 1.850 \%, 2.167 \%, 2.033 \%, 2.367 \%, 2.267 \%$, $1.983 \%, 2.400 \%, 3.1000 \%$ and $2.132 \%$ respectively. The low fibre content in tea sample under investigation may be due to the use of impurities such as stem during processing. In addition, the 
crushing, tearing and cutting processes also destroy the leaf structure that might have effect in the fibre content as reported. [8]. Previous also indicated positive correlation between fibre content and keeping quality of tea and proposed fibre of less than $16.5 \%$ in order to maintain high quality tea during storage [9].

The ash contents for all the tea bags ranged from 3.667-5.133\%. A similar research reported 4.9-6.5\% ash contents for black tea and 6.1-9.2\% for green tea respectively [3]. However, less ash content in tea sample might be due to adulteration during processing using inferior materials for the extraction process and this will lead to tea sample of inferior quality as observed [10]. Also, a previous work indicated positive association between ash content and keeping quality of the tea and proposed that ash content should be controlled at less than $5.54 \%$ in order to maintain better quality of tea during storage [11].

The constituent that are of importance in relation to the overall flavor of tea are the caffeine, tannin and the volatile oil [3]. The caffeine contents in the samples varied between $0.207 \%$ and $1.833 \%$.A similar work reported 1.9-3.6\% caffeine contents for black tea and 1.5-4.3\% for green tea respectively [3]. Caffeine, being an important component of tea is essential for the efficiency and taste characteristics of commercial tea and regarded as an important parameter for commercial tea evaluation.

The quality of black tea is strongly associated with amount of caffeine content for the formation of precipitates during infusion process

The Tannin content in commercial tea bags is an important quality parameter for determining the tea quality. The tannin contents as revealed by the result of the analysis were $6.133 \%, 5.467 \%, 7.567$, $7.700 \%, 7.500 \%, 7.367 \%, 7.400 \%, 7.133 \%, 6.500 \%$ and $7.687 \%$ respectively. Tannin contents of 7.3$15.1 \%$ for black tea was reported earlier [3] as shown in table 1. A work carried out [12] reported that higher tannin content may be due to the use of fresh leaves without oxidation while low tannin content are due to enzymatic oxidation process. Except for three (3) of the samples under consideration, which showed lower levels of tannin, all other samples are in agreement with a previous work [3]

Acid insoluble matter ranged from $1.100 \%-3.667 \%$, potassium salt varied between $14.850 \%$ and $17.067 \%$ while nitrogenous matter ranged from $1.260 \%-1.833 \%$ respectively for all the samples.

\section{Conclusion}

This study has revealed the wholesomeness or otherwise of tea bags commercially available in Ogun state, south west, Nigeria since there have been cases of adulteration in most foods, especially tea bags as they do not contain nutrient claimed on their labels.

\section{ACKNOWLEDGEMENT}

The Author wishes to acknowledge the contributions of Olumomi, Elizabeth Ayobami and Osayemi, Oluwagbemisola Victor in providing technical assistance in the course of this work.

\section{REFERENCES}

[1] Wikipedia Encyclopedia (2005)

[2] Cabrera, C, Gimenez, R and Lopez, M.C (2003): Determination of tea component with Antioxidant activity. Journal of Agricultural and Food Chemistry.51:4427-4435

[3] Kirk, P.S, and Sawyer, R (1991). Beverages and Chocolate In: Pearsons Composition and Analysis of food $9^{\text {th }}$ edition. Longman Group Limited. UK:356-390

[4] Zeng, S, LI, Q and Shuke, L(2003): Effect of Herbal infusion, Tea and Carbonated Beverage on Alcohol Dehydrogen and Aldehydl Dehydrogenase activity

[5] Kharat, T and Bhagat, R.M (2010). Trace Element in Tea Leaves. Made Tea and Tea Infusion. A Review: Food Research International. 43:2234-2252

[6] Yao, L, X Liu, X, Jing, Y and Gaffin, N(2006) Compositional Analysis of Teas from Australian Supermarkets. Food Chemistry.94:115-112 
[7] Vankatesan, S, Senthurpandia, V.K, Maurugase, S , Miabuam W and Ganapathy. G.(2006). Quality Standard of CTC Black Teas as influenced by source of potassium fertilizer. Journal of food science and Agriculture 85:799-803

[8] Smiechowska, M and Dmowski, P(2006): Crude Fibre as a Parameter in the Quality Evaluation of Tea. Food Chemistry. 94:367-368

[9] Ismail, M.E, Daniel,A.M, Rahmat, Aand Yahaya, A (2000). Chemical Composition and Antioxidant Activity of strobilanthes Crispul Leaf. Extract Journal of Nutrition and Biochemistry. 11:536-542

[10] Rehman, S.U, Almas, K, Shahzadi, N, Saleem, A. and Batti, N. (2002). Effect of Time and Temperature on Infusion of Tannins from Commercial Brands of Tea. International Journal of Agricultural Biochemical. 285-288

[11] Chung, K.T, Wong T.Y, Wei, C.I, Huang, Y.W and Lin,Y(1998) Tannin and Human Health:, A critical review in food science and nutrition:38(6) 421-464 